\title{
The role of CRP, PCT, IL-6 and presepsin in early diagnosis of bacterial infectious complications in paediatric haemato-oncological patients
}

\author{
M. PLESKO ${ }^{1, *}$, J. SUVADA ${ }^{2}$, M. MAKOHUSOVA ${ }^{1,3}$, I. WACZULIKOVA ${ }^{4}$, D. BEHULOVA ${ }^{5}$, A. VASILENKOVA ${ }^{5}$, M. VARGOVA ${ }^{6}$, A. STECOVA ${ }^{7}$, \\ E. KAISEROVA ${ }^{1}$, A. KOLENOVA ${ }^{1, *}$
}

${ }^{1}$ Department of Paediatric Haematology and Oncology, Children's Teaching Hospital with Policlinic, Medical Faculty of Comenius University, Bratislava, Slovakia; ${ }^{2}$ College of Health Service and Social Work of St. Elizabeth, Bratislava, Slovakia; ${ }^{3}$ Department of Chemistry, Faculty of Natural Sciences, University of St. Cyril and Methodius in Trnava, Trnava, Slovakia; ${ }^{4}$ Department of Nuclear Physics and Biophysics, Faculty of Mathematics, Physics and Informatics, Comenius University, Bratislava, Slovakia; ${ }^{5}$ Department of Laboratory Medicine, Children's Teaching Hospital with Policlinic, Bratislava, Slovakia; ${ }^{6}$ Department of Laboratory Medicine, St. Elisabeth Cancer Institute, Bratislava, Slovakia; ${ }^{7}$ Hospital Laboratory, MEDIREX, Teaching Hospital, Bratislava, Slovakia

•Correspondence: marekplesko@gmail.com,sasa.kolenova@gmail.com

Received November 24, 2015 / Accepted March 23, 2016

\begin{abstract}
Bacterial infection is the most common complication in paediatric oncological patients during cancer treatment. A suitable tool for early prediction of unfavourable course of infection is still needed. We performed a prospective longitudinal observational study to evaluate of the role of serum biomarkers (C-reactive protein, procalcitonin, interleukin-6, presepsin) in the early diagnosis of bacteraemia (gram-negative versus gram-positive) in patients with haematological malignancies. We observed 69 febrile episodes in 33 patients (17 male, 16 female; $1.5-18.9$ years, mean 7.31 years, median 5 years). Within this sample, there were 22 cases of positive blood cultures, 16 cases of sepsis, 38 cases of fever with no signs or symptoms of sepsis, and two deaths from infectious complications. All markers tested had good negative predictive value $(73 \%-93 \%)$. CRP was characterized by good specificity for registration bacteraemia (96\%, 95\% CI: $85 \%-99 \%)$, but other results were inconclusive. We identified comparably balanced sensitivity $(64 \%-81 \%)$ and specificity $(61 \%-88 \%)$ for interleukin-6 and procalcitonin, and we proved their quality to predict positive blood culture and clinical signs of sepsis as well. Patients with gram-negative bacteraemia had significantly elevated levels of PCT and IL-6 in comparison with a group of patients with gram-positive bacteraemia ( $\mathrm{p}=0.04$ for PCT and $\mathrm{p}=0.005$ for IL-6). Presepsin was characterized by poor specificity $(27 \%$, $95 \%$ CI: $15 \%-43 \%)$ and positive predictive value (24\%, 95\% CI: 12 - 39\%) for predicting bacteraemia, and by better sensitivity (84\%, 95\% CI: 55\% - 98\%) and specificity (58\%, 95\% CI: 42\% - 73\%) for predicting clinical signs of sepsis.
\end{abstract}

Key words: C-reactive protein, procalcitonin, interleukin-6, presepsin, fever, sepsis

Bacterial infection is the most common treatment-related complication in patients with haematological malignancies [1]. Documented mortality associated with paediatric febrile neutropenia is $2 \%$ [2]. The potential for early diagnosis of bacteraemia through serum biomarkers has been the subject to extensive research [3]. In 2012 Phillips et al published large meta-analysis of 25 studies exploring 14 different biomarkers in 3,585 episodes of febrile neutropenia. CRP, PCT and IL- 6 were subject to quantitative meta-analysis. The bivariate estimates of diagnostic precision of these biomarkers and outcomes were done. Data were available for meta-analysis for CRP for microbiologically or clinically documented infection (results: cut off $>50 \mathrm{mg} / \mathrm{dl}$, sensitivity $65 \%$, specifi- city 73\%), for PCT assessing microbiologically or clinically documented infection (results: cut off $>0.2 \mathrm{mg} / \mathrm{ml}$, sensitivity $96 \%$, specificity $85 \%$ ), for IL-6 reporting microbiologically or clinically documented infection (results: cut off $>235$ $\mathrm{pg} / \mathrm{ml}$, sensitivity $68 \%$, specificity $94 \%$ ), and gram-negative bacteraemia (results: cut off $>1000 \mathrm{pg} / \mathrm{ml}$, sensitivity $78 \%$, specificity 96\%). Huge inconsistencies and heterogeneity in the studies included in this review were the most important limiting factors [4].

The most widely clinically used markers are C-reactive protein (CRP) and procalcitonin (PCT). Some studies have found correlation between CRP and duration of fever and clinical severity of febrile neutropenic episodes, but these findings 
have not been consistently replicated [4-7]. CRP levels also increase slowly relative to cytokines and PCT [3, 4]. Data for the improved predictive value of PCT are quite varied too [8]. Based on some existing data, PCT is not yet be recommended for use in routine clinical practice $[9,10]$. However, an abovementioned meta-analysis of 14 different biomarkers, including PCT, indicated that PCT appears promising and should be subject to new primary studies investigating the prediction of significant infectious morbidity [4].

Cytokines are detected in serum in the early stages of infection, and particularly in bacterial infections, they may be higher than CRP in early disease $[4,11,12,35]$. IL-6, IL-8, and IL-10 have been shown to have good negative predictive value for bacteraemia in adult and paediatric oncology patients [4, $6,13]$. Some of them are perspective for further optimize the risk assessment model, because there is no generally accepted method that can rapidly differentiate between paediatric oncology patients with febrile neutropenia (FN) who are at high risk for developing adverse events (AEs) and those at low risk for AEs [14].

Presepsin (soluble sCD14 subtype, sCD14-ST) is a circulating molecule fragment derived from sCD14 and serves as mediator of lipopolysaccharid response against infectious agents. More recent studies have presented presepsin as a valuable potential biomarker for early diagnosis of sepsis, risk stratification and evaluation of prognosis in adult patients in the emergency department. Presepsin was superior to IL-6, CRP and PCT with regard to discriminating between survivors and non-survivors, and between low-grade sepsis versus severe sepsis or septic shock $[15,16]$. Presepsin has seldom been studied in paediatric patients and results thus far are inconclusive [17 - 21].
Only few studies have concentrated on use of routinely available biomarkers (CRP, PCT) for optimizing antibiotic therapy. Several studies tested the utility of CRP measurements for shortening the duration of anti-infective therapy. Use of CRP may be limited in children to help discontinuing therapy, but evidence is poor [22 - 24]. Procalcitonin can be also a useful tool to shorten the duration of antibiotic therapy. According to rare paediatric studies, inclusion of PCT measurements within decision algorithms of antibiotic management for specific infections may be appropriate in neonates and young children under 36 months $[25,26]$.

Characteristics of the most frequently investigated markers are summarized in Table 1.

\section{Patients and methods}

We performed a prospective longitudinal observational study to evaluate the role of serum biomarkers (CRP, PCT, IL-6, presepsin) in early diagnosis of bacteraemia or its signs in patients suffering from haematological malignancies. We established the main characteristics for each marker (cut-off level, sensitivity, specificity, positive predictive value [PPV], negative predictive value $[\mathrm{NPV}]$ ) following three study questions:

- Which of markers are the best for prediction of positive blood culture?

- Which of markers are the best for prediction of signs of sepsis?

- Which of markers are the best correlates with specific type of bacteraemia (gram positive versus gram negative)?

Patients. Children aged 0 to 18.9 years, with a primary diagnosis of a haematological malignancy, who were admitted

Table 1. Main characteristic of biomarkers

\begin{tabular}{|c|c|c|c|c|c|c|}
\hline Marker & Type & Time of increasing & Peak level & $\begin{array}{l}\text { Half time } \\
+ \text { cut off }\end{array}$ & Advantage & Disadvantage \\
\hline CRP & APP & $4-6 \mathrm{~h}$ & $36-48 \mathrm{~h}$ & $\begin{array}{c}19 \mathrm{~h} \\
10 \mathrm{mg} / \mathrm{l}^{*}\end{array}$ & $\begin{array}{c}\text { Availability } \\
\text { Routinely used }\end{array}$ & $\begin{array}{l}\text { Increase of the level is influ- } \\
\text { enced by cancer treatment }\end{array}$ \\
\hline PCT & Pro-hormone & $3-4 \mathrm{~h}$ & $8-24 \mathrm{~h}$ & $\begin{array}{c}48 \mathrm{~h} \\
0.5 \mu \mathrm{g} / \mathrm{l}^{*}\end{array}$ & $\begin{array}{c}\text { Predictor of mortality } \\
\text { Possible tool for shorten } \\
\text { ATB therapy }\end{array}$ & $\begin{array}{c}\text { Limitations in neonates and } \\
\text { transplanted patients } \\
\text { (using ATG) }\end{array}$ \\
\hline IL-6 & Cytokine & $1 \mathrm{~h}$ & $4 \mathrm{~h}$ & $\begin{array}{c}8 \mathrm{~h} \\
7.0 \mathrm{ng} / \mathrm{l}^{\star}\end{array}$ & $\begin{array}{c}\text { Good NPV } \\
\text { Predictor of neonatal } \\
\text { sepsis } \\
\text { Very early top level! } \\
\end{array}$ & $\begin{array}{c}\text { Increase during autoimmune } \\
\text { diseases, burns, traumas } \\
\text { as well }\end{array}$ \\
\hline Presepsin & $\mathrm{sCD} 14^{\star *}$ & $2 \mathrm{~h}$ & $3 \mathrm{~h}$ & $\begin{array}{c}4-5 \mathrm{~h} \\
\text { Mild sepsis: } \\
338-950 \mathrm{ng} / \mathrm{l}^{\star} \\
\text { Severe sepsis/Septic shock: } \\
>950 \mathrm{ng} / \mathrm{l}^{\star}\end{array}$ & $\begin{array}{l}\text { Predictor of mortality } \\
\text { Ability distinguish sep- } \\
\text { sis from SIRS }\end{array}$ & Little data in paediatrics \\
\hline
\end{tabular}

CRP: C-reactive protein, PCT: Procalcitonin, IL-6: Interleukin-6, APP: acute-phase protein, NPV: negative predictive value, ATB: antibiotics, SIRS: Systemic Inflamatory Response Syndrome, ATG: Anti-thymocyte globulin

Sources: $[3,4,6,7,10,11,15,16,25-30,35]$

${ }^{*}$ cut off levels established by standards of cooperating laboratories

${ }^{* *} \mathrm{CD} 14$ is glycoprotein expressed on the membrane surface of monocytes/macrophages and its soluble fragment called presepsin 
to the inpatient paediatric oncology service from November 2013 to May 2015 were eligible to enroll. Written informed consent was obtained from parents or legal guardians of all enrolled children. Study was specified by protocol. The primary inclusion criterion was the presence of fever, hypothermia, chills, or another sign of possible sepsis. We excluded patients with febrile episodes thought to be an adverse effect of chemotherapy, patients who did not have blood cultures drawn (for example, due to central venous catheter malfunction) and patients with proven non-bacterial infection. The study was approved by the ethical committee of Children's Teaching Hospital with Policlinic in Bratislava, Slovakia.

Procedure sampling and analysis. Blood samples for detection of biomarkers were drawn concomitantly with blood culture, prior to administration of antibiotics. All samples (markers and blood culture) were collected during the initial episode; repeated sampling was performed in clinically unstable patients. Laboratory standard cut-off values for abnormal levels of considered markers were: $10 \mathrm{mg} / \mathrm{l}$ for CRP; $0.5 \mu \mathrm{g} / \mathrm{l}$ for PCT; $7.0 \mathrm{ng} / \mathrm{l}$ for IL-6; and $338 \mathrm{ng} / \mathrm{l}$ for presepsin. Investigation of serum CRP was performed by using analyser VITROS Fusion 5.1 (OrthoClinical Diagnostics, Rochester, USA). Determination of CRP was based on an enzymatic heterogeneous, sandwich immunoassay format. Analyses of serum PCT; and also serum IL-6, were determined on cobas E-411 analyser (Roche, Basel, Switzerland) by the electrochemiluminescence immunoassay "ECLIA". Analysis of Presepsin (CD14) was based on non-competitive chemiluminiscent enzyme immunoassay (CLEIA) combined with ${ }^{*}$ MAGITRATION ${ }^{\circ}$ technology using analyser Pathfast Mitsubishi.

Statistical analysis. The receiver operating characteristic (ROC) curve was used for determination of the cut-off level for the particular markers; we choose cut-off value that maximizes the sum of sensitivity and specificity. The result of combination of biomarkers was considered positive if at least one of biomarker result was positive. The quality of biomarker was assessed using the sensitivity, specificity, positive predictive value (PPV), and negative predictive value (NPV). The difference between gram positive and gram negative bacteria in investigated markers was analysed using the unpaired T-test. The results were considered statistically significant when $\mathrm{p}<$ 0.05 . Statistical analyses were performed using the StatsDirect version 2.8.0 statistical software StatsDirect Ltd. http://www. statsdirect.com.

Definitions of basic terms. Fever was defined as an axillary body temperature greater than $38.0^{\circ} \mathrm{C}$ in one measurement lasting more than one hour, or a temperature greater than $38.5^{\circ} \mathrm{C}$ measured at a single time. Neutropenia was defined as an absolute neutrophil count (ANC) less than $0.5 \times 10^{9} / 1$ or an ANC $\leq 1.0 \times 10^{9} / 1$ expected to decrease to an ANC less than $0.5 \times 10^{9} / 1$. Bacteraemia was defined as a positive blood culture, independent of clinical signs of sepsis. Sepsis was defined as a set of clinical symptoms: temperature greater than $38^{\circ} \mathrm{C}$ or less than $36^{\circ} \mathrm{C}$, tachycardia, tachypnea, other clinical symptoms, signs or test results associated with infection (e.g., radiographically-confirmed pneumonia, CSF-confirmed meningitis, petechiae, purpura, etc.), and/or signs of multiple organ dysfunction or failure (e.g., alteration of mental status, hypotension, oliguria, increase in transaminases, bilirubin, disseminated intravascular coagulation etc.) [13]. Fever of unknown origin (FUO) was defined as a febrile episode with confirmed negative blood culture, absence of sepsis, and clinically or microbiologically documented local infection.

\section{Results}

The study group (Table 2) was characterized by heterogeneous clinical symptomatology and presentation of risk factors (severity of neutropenia) what is resumed in Table 3 . Of the 22 positive blood cultures, only seven of these patients developed sepsis. In another nine cases of clinical sepsis, blood cultures were negative.

Table 2. Patient characteristic

\begin{tabular}{|c|c|}
\hline Parameter & Result \\
\hline Boys/Girls & $17: 16$ \\
\hline The age range* & $1.5-18.9$ years \\
\hline Average age* & 7.31 years \\
\hline The median* & 5 years \\
\hline Number of febrile episodes & 69 febrile episodes in 33 patients \\
\hline Number of febrile episodes with manifested signs of sepsis & 16 episodes in 12 patients \\
\hline Number of positive blood culture & 22 episodes in 12 patients \\
\hline Number of neutropenic episodes & 58 (84.05\%): $91.53 \%$ ratio of ANC $\leq 0.5 \times 10^{9} / 1$ \\
\hline Average time from the beginning of neutropenia to the first signs of potential infection & 11.43 days (the median 6 days) \\
\hline Spectrum of diagnosis & 24 cases of ALL, 6 cases of AML, 3 cases of NHL \\
\hline Deaths & $\begin{array}{l}\text { Two patients due to infectious complication and two patients because } \\
\text { of their disease progression. }\end{array}$ \\
\hline
\end{tabular}

${ }^{\star}$ Each age parameter was registered at the time of the event (signs of potential infection with taking the blood culture sample)

ALL: acute lymphoblastic leukaemia, AML: acute myeloid leukaemia, NHL: Non-Hodgkin lymphoma 


\section{CRP- ROC plots}

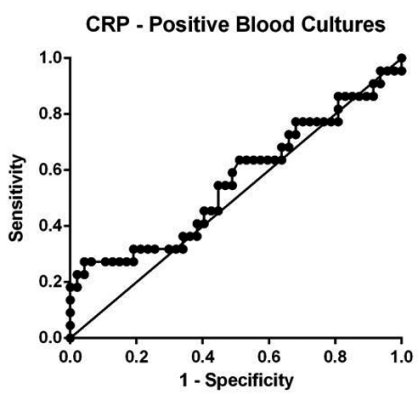

Area under ROC curve $=0.564$

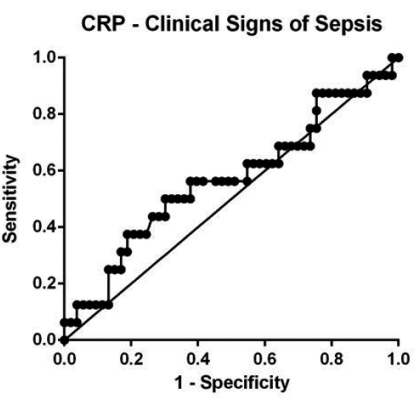

Area under ROC curve $=0.570$

\section{IL-6 - ROC plots}

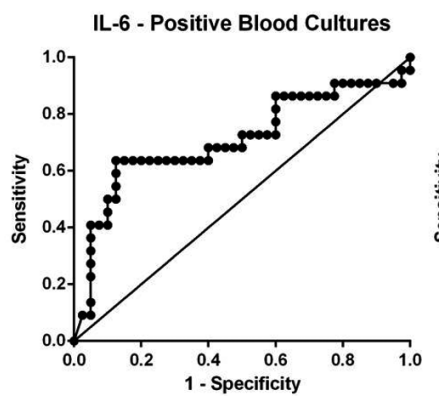

Area under ROC curve $=0.709$

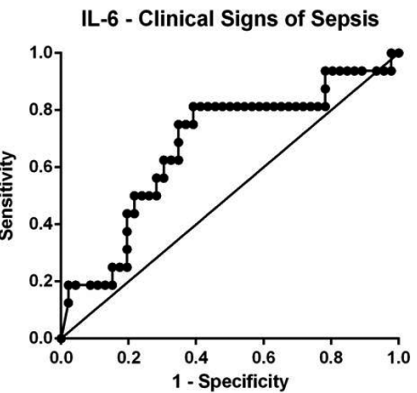

Area under ROC curve $=0.674$

Figure 1. ROC analysis of the biomarker performance

Our data showed various outcomes for each marker in different situations (Results are summarized in Table 4 and Table 5 and relevant ROC curves are shown in Figure 1). CRP analysis revealed high specificity and higher cut-off level for predicting bacteraemia compared to sepsis $(76.3 \mathrm{mg} / \mathrm{l}$ versus $49.4 \mathrm{mg} / \mathrm{l}$ ), while sensitivity, PPV and NPV were higher in case of manifested sepsis.

PCT analysis showed better sensitivity for diagnostic bacteraemia and better specificity for registration signs of sepsis. PPV and NPV are nearly identical for both situations, but NPV riches better results. Cut off value of PCT is higher in septic patients $(0.68 \mu \mathrm{g} / \mathrm{l}$ versus $0.25 \mu \mathrm{g} / \mathrm{l})$. IL- 6 examination is presented by preferable specificity for detection of positive blood culture and good sensitivity for early sepsis identification. We noted high NPV in both clinical circumstances; PPV achieves better result in diagnosis of bacteraemia. Calculated cut off level of IL-6 is higher during the episodes with proven positive blood culture (196.6 ng/l versus $106.1 \mathrm{ng} / \mathrm{l})$. We confirmed good NPV in both of these markers (PCT, IL-6) and found out small differences in specificity and sensitivity ratio for predicting two different clinical situations.

Presepsin predicted with 12 cases of positive blood culture (of 22 cases total) and 13 cases of documented sepsis (of 16 cases total). We found out quite good sensitivity ( $83 \%$ and

\section{PCT- ROC plots}

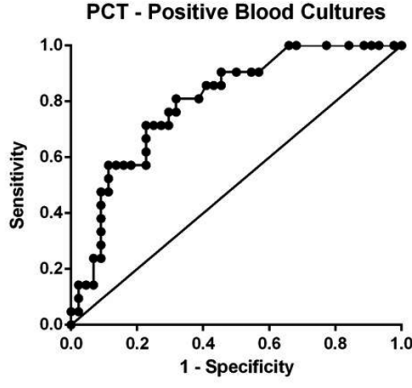

Area under ROC curve $=0.798$

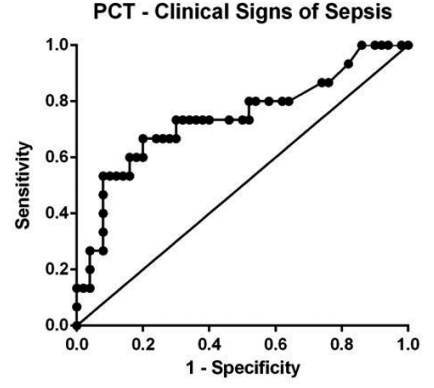

Area under ROC curve $=0.740$

\section{Presepsin - ROC plots}

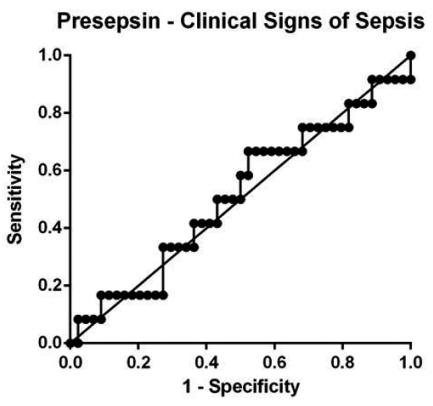

Area under ROC curve $=0.489$

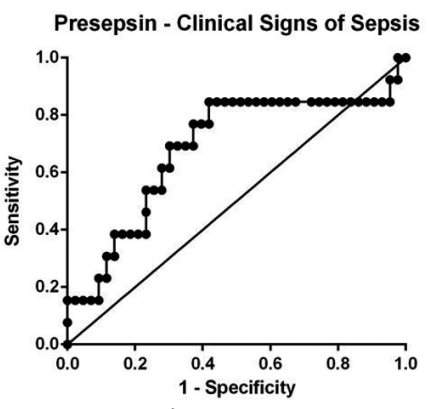

Area under ROC curve $=0.683$
84\%) and NPV (86\% and 93\%) in predicting bacteraemia and also septic status in patients. We concluded PPV and specificity of this biomarker as poor ones. Specificity reached a better result in ability to predict clinical signs of sepsis (58\% versus $27 \%$ ). Calculated cut off levels are lower than officially laboratory used thresholds values $(240 \mathrm{ng} / \mathrm{l}$ and $299 \mathrm{ng} / \mathrm{l}$ versus $338 \mathrm{ng} / \mathrm{l})$.

Table 3. Clinical characteristic

\begin{tabular}{cc}
\hline \multicolumn{2}{c}{$\mathbf{6 9}$ febrile episodes in 33 patients } \\
\hline $\mathbf{2 2}$ episodes of positive blood culture (31.89\%) in $\mathbf{1 2}$ patients $\mathbf{( 3 6 . 3 6 \% )}$ \\
\hline $\mathbf{n}$ & $\mathbf{\%}$ \\
\hline 7 times signs of sepsis & $31.8 \%$ \\
15 times fever without signs of sepsis & $68.2 \%$ \\
20 times neutropenia: & $90.1 \%$ \\
(17 times ANC $\left.\leq 0.5 \times 10^{9} / 1\right)$ & $(85.0 \%)$ \\
\hline $\mathbf{4 7}$ episodes of negative blood culture $\mathbf{( 6 8 . 1 1 \% )}$ in $\mathbf{2 1}$ patients $\mathbf{( 6 3 . 6 4 \% )}$ \\
\hline $\mathbf{n}$ & $\mathbf{\%}$ \\
\hline 9 times signs of sepsis & $19.2 \%$ \\
38 times fever without signs of sepsis & $80.9 \%$ \\
38 times neutropenia: & $80.9 \%$ \\
(35 times ANC $\left.\leq 0.5 \times 10^{9} / 1\right)$ & $(92.1 \%)$ \\
\hline
\end{tabular}


We also performed an analysis of combinations of markers using our calculated cut-off values. The summary is presented in Table 6 and Table 7.

Our results, visualised in Table 8 and Figure 2, showed significant difference for marker PCT $(\mathrm{p}=0.040)$ and IL6 ( $\mathrm{p}=$ 0.005 ) between gram positive and negative bacteraemia.

\section{Discussion}

Many studies examined role of biomarkers in detecting initial bacteraemia or another microbiologically confirmed infection. Same reviews even excluded patients with fever of unknown origin. On the other hand, there are also papers assessing value

Table 4. Biomarkers analysis - relation to positive blood culture

\begin{tabular}{|c|c|c|c|c|c|c|}
\hline & $\mathbf{n}^{*}$ & Cut-off & Sensitivity (95\% CI) & $\begin{array}{c}\text { Specificity } \\
(95 \% \text { CI })\end{array}$ & $\begin{array}{c}\text { PPV } \\
(95 \% \mathrm{CI})\end{array}$ & $\begin{array}{c}\text { NPV } \\
(95 \% \mathrm{CI})\end{array}$ \\
\hline CRP & 69 & $76.3 \mathrm{mg} / \mathrm{l}$ & $\begin{array}{c}0.27 \\
(0.11-0.50) \\
\end{array}$ & $\begin{array}{c}0.96 \\
(0.85-0.99) \\
\end{array}$ & $\begin{array}{c}0.75 \\
(0.35-0.97) \\
\end{array}$ & $\begin{array}{c}0.73 \\
(0.60-0.84) \\
\end{array}$ \\
\hline PCT & 65 & $0.25 \mu \mathrm{g} / 1$ & $\begin{array}{c}0.81 \\
(0.58-0.94)\end{array}$ & $\begin{array}{c}0.68 \\
(0.52-0.81)\end{array}$ & $\begin{array}{c}0.54 \\
(0.36-0.73)\end{array}$ & $\begin{array}{c}0.88 \\
(0.73-0.97)\end{array}$ \\
\hline IL-6 & 62 & $196.6 \mathrm{ng} / \mathrm{l}$ & $\begin{array}{c}0.64 \\
(0.41-0.83) \\
\end{array}$ & $\begin{array}{c}0.88 \\
(0.73-0.96) \\
\end{array}$ & $\begin{array}{c}0.74 \\
(0.48-0.91) \\
\end{array}$ & $\begin{array}{c}0.81 \\
(0.67-0.92) \\
\end{array}$ \\
\hline Presepsin & 55 & $240.0 \mathrm{ng} / 1$ & $\begin{array}{c}0.83 \\
(0.52-0.98)\end{array}$ & $\begin{array}{c}0.27 \\
(0.15-0.43)\end{array}$ & $\begin{array}{c}0.24 \\
(0.12-0.39)\end{array}$ & $\begin{array}{c}0.86 \\
(0.58-0.98)\end{array}$ \\
\hline
\end{tabular}

${ }^{*}$ Number of investigations

CI: confidence interval, $\mathrm{PPH}$ : positive predictive value, NPH: negative predictive value

Table 5. Biomarkers analysis - relation to signs of sepsis

\begin{tabular}{|c|c|c|c|c|c|c|}
\hline & $\mathbf{n}^{*}$ & Cut off & Sensitivity $(95 \% \mathrm{CI})$ & $\begin{array}{l}\text { Specificity } \\
(95 \% \mathrm{CI})\end{array}$ & $\begin{array}{c}\text { PPV } \\
(95 \% \text { CI })\end{array}$ & $\begin{array}{c}\text { NPV } \\
(95 \% \text { CI })\end{array}$ \\
\hline CRP & 69 & $49.4 \mathrm{mg} / \mathrm{l}$ & $\begin{array}{c}0.50 \\
(0.25-0.75)\end{array}$ & $\begin{array}{c}0.71 \\
(0.57-0.82)\end{array}$ & $\begin{array}{c}0.35 \\
(0.16-0.57)\end{array}$ & $\begin{array}{c}0.82 \\
(0.68-0.92)\end{array}$ \\
\hline PCT & 65 & $0.68 \mu \mathrm{g} / \mathrm{l}$ & $\begin{array}{c}0.67 \\
(0.38-0.88)\end{array}$ & $\begin{array}{c}0.80 \\
(0.66-0.90)\end{array}$ & $\begin{array}{c}0.50 \\
(0.27-0.73)\end{array}$ & $\begin{array}{c}0.89 \\
(0.76-0.96)\end{array}$ \\
\hline IL-6 & 62 & 106 ng/l & $\begin{array}{c}0.81 \\
(0.54-0.96)\end{array}$ & $\begin{array}{c}0.61 \\
(0.45-0.75)\end{array}$ & $\begin{array}{c}0.42 \\
(0.25-0.61)\end{array}$ & $\begin{array}{c}0.90 \\
(0.74-0.98)\end{array}$ \\
\hline Presepsin & 55 & 299 ng/l & $\begin{array}{c}0.84 \\
(0.55-0.98) \\
\end{array}$ & $\begin{array}{c}0.58 \\
(0.42-0.73) \\
\end{array}$ & $\begin{array}{c}0.37 \\
(0.21-0.58) \\
\end{array}$ & $\begin{array}{c}0.93 \\
(0.76-0.99)\end{array}$ \\
\hline
\end{tabular}

${ }^{*}$ Number of investigations

CI: confidence interval, $\mathrm{PPH}$ : positive predictive value, NPH: negative predictive value

Table 6. Analysis of biomarker's combinations - relation to positive blood culture

\begin{tabular}{|c|c|c|c|c|c|}
\hline Combinations of biomarkers & $\mathbf{N}^{*}$ & Sensitivity (95\% CI) & $\begin{array}{c}\text { Specificity } \\
(95 \% \text { CI })\end{array}$ & $\begin{array}{c}\text { PPV } \\
(95 \% \text { CI }) \\
\end{array}$ & $\begin{array}{c}\text { NPV } \\
(95 \% \text { CI }) \\
\end{array}$ \\
\hline CRP + PCT & 65 & $\begin{array}{c}0.81 \\
(0.58-0.94) \\
\end{array}$ & $\begin{array}{c}0.63 \\
(0.47-0.78) \\
\end{array}$ & $\begin{array}{c}0.52 \\
(0.34-0.69) \\
\end{array}$ & $\begin{array}{c}0.87 \\
(0.71-0.96) \\
\end{array}$ \\
\hline CRP + IL-6 & 62 & $\begin{array}{c}0.68 \\
(0.45-0.86) \\
\end{array}$ & $\begin{array}{c}0.83 \\
(0.67-0.92) \\
\end{array}$ & $\begin{array}{c}0.68 \\
(0.45-0.86) \\
\end{array}$ & $\begin{array}{c}0.83 \\
(0.67-0.92) \\
\end{array}$ \\
\hline PCT + IL-6 & 59 & $\begin{array}{c}0.54 \\
(0.36-0.72) \\
\end{array}$ & $\begin{array}{c}0.88 \\
(0.70-0.98) \\
\end{array}$ & $\begin{array}{c}0.86 \\
(0.64-0.97) \\
\end{array}$ & $\begin{array}{c}0.61 \\
(0.43-0.76) \\
\end{array}$ \\
\hline Presepsin + CRP & 55 & $\begin{array}{c}0.75 \\
(0.43-0.95) \\
\end{array}$ & $\begin{array}{c}0.25 \\
(0.13-0.40)\end{array}$ & $\begin{array}{c}0.21 \\
(0.10-0.37)\end{array}$ & $\begin{array}{c}0.78 \\
(0.49-0.95)\end{array}$ \\
\hline Presepsin + PCT & 53 & $\begin{array}{c}1.00 \\
(0.73-1.00) \\
\end{array}$ & $\begin{array}{c}0.17 \\
(0.07-0.32) \\
\end{array}$ & $\begin{array}{c}0.26 \\
(0.14-0.41) \\
\end{array}$ & $\begin{array}{c}1.00 \\
(0.59-1.00) \\
\end{array}$ \\
\hline Presepsin + IL-6 & 49 & $\begin{array}{c}0.75 \\
(0.43-0.95) \\
\end{array}$ & $\begin{array}{c}0.27 \\
(0.14-0.44) \\
\end{array}$ & $\begin{array}{c}0.25 \\
(0.12-0.42) \\
\end{array}$ & $\begin{array}{c}0.77 \\
(0.46-0.95) \\
\end{array}$ \\
\hline
\end{tabular}

${ }^{*}$ Number of investigations

CI: confidence interval, $\mathrm{PPH}$ : positive predictive value, NPH: negative predictive value 

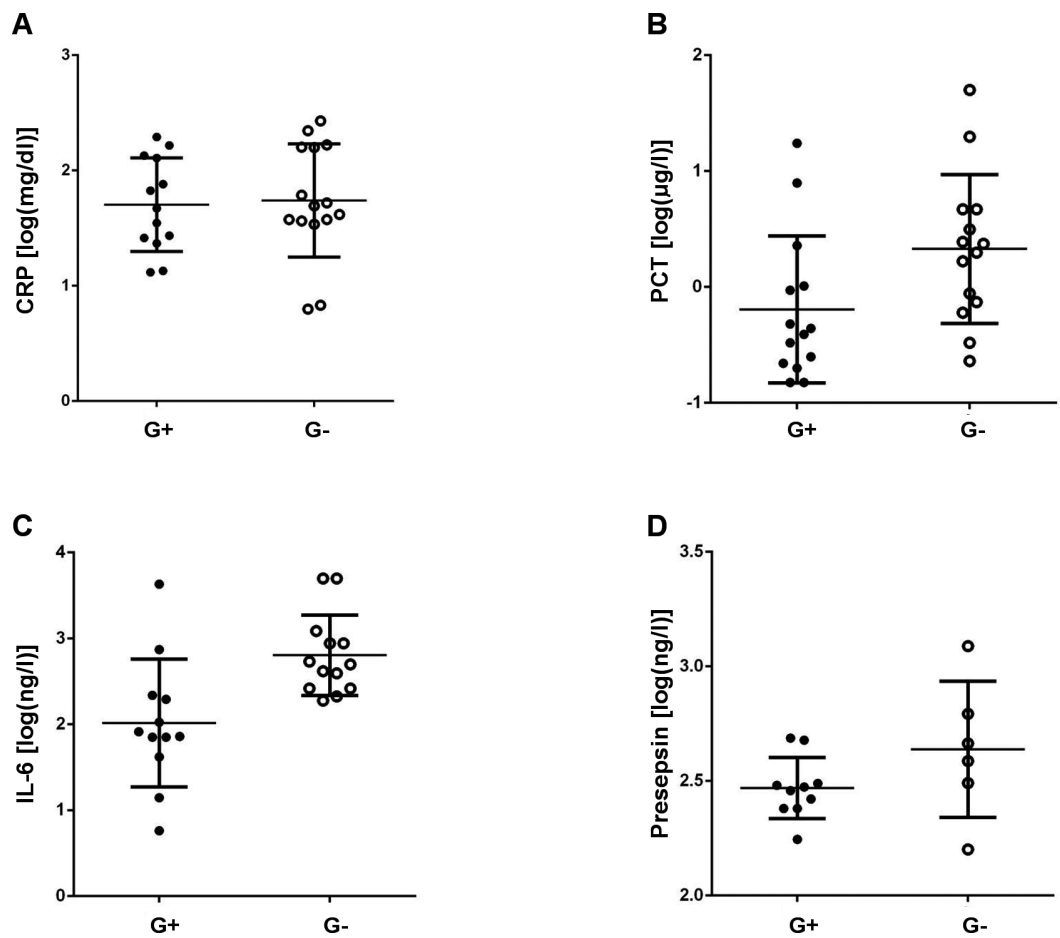

Figure 2. Scatter plots - differences in biomarker levels between gram positive and gram negative bacteraemia

of markers in context of predicting clinically manifested potential infectious complication independently of microbiologically documented etiological agents [4]. We consider clinical signs of infection/sepsis are more relevant for patient's prognosis than assessment based predominantly on microbiologically proven positive blood culture. This opinion is also supported by recent studies and by our empirical experience as well $[14,31]$.

Identification of laboratory markers to efficiently and accurately stratify for patients based on risk of serious infectious complication is badly needed in paediatric oncology $[14,32]$. Our results for PCT and IL- 6 are presented by slightly smaller values of sensitivity and specificity than results of abovementioned meta-analysis published by Philips et al. or other single studies $[4,6,33]$. Despite this fact we concluded that PCT and IL- 6 were the most promising markers for further analysis.

According Sklavou et al. the change rate of CRP over time is offered as a prognostic index of bacterial infection

Table 7. Analysis of biomarker's combinations - relation to signs of sepsis

\begin{tabular}{|c|c|c|c|c|c|}
\hline Combinations of biomarkers & $\mathbf{N}^{*}$ & Sensitivity (95\% CI) & $\begin{array}{c}\text { Specificity } \\
(95 \% \text { CI })\end{array}$ & $\begin{array}{c}\text { PPV } \\
(95 \% \mathrm{CI})\end{array}$ & $\begin{array}{c}\text { NPV } \\
(95 \% \text { CI })\end{array}$ \\
\hline $\mathrm{CRP}+\mathrm{PCT}$ & 65 & $\begin{array}{c}0.67 \\
(0.38-0.88) \\
\end{array}$ & $\begin{array}{c}0.54 \\
(0.39-0.68) \\
\end{array}$ & $\begin{array}{c}0.30 \\
(0.16-0.49) \\
\end{array}$ & $\begin{array}{c}0.84 \\
(0.67-0.95) \\
\end{array}$ \\
\hline CRP + IL-6 & 62 & $\begin{array}{c}0.88 \\
(0.62-0.98)\end{array}$ & $\begin{array}{c}0.39 \\
(0.25-0.55)\end{array}$ & $\begin{array}{c}0.33 \\
(0.20-0.50)\end{array}$ & $\begin{array}{c}0.90 \\
(0.68-0.99)\end{array}$ \\
\hline PCT + IL-6 & 59 & $\begin{array}{c}0.87 \\
(0.60-0.98) \\
\end{array}$ & $\begin{array}{c}0.50 \\
(0.35-0.65) \\
\end{array}$ & $\begin{array}{c}0.37 \\
(0.21-0.55) \\
\end{array}$ & $\begin{array}{c}0.92 \\
(0.73-0.99) \\
\end{array}$ \\
\hline Presepsin + CRP & 55 & $\begin{array}{c}0.77 \\
(0.46-0.95)\end{array}$ & $\begin{array}{c}0.42 \\
(0.27-0.58)\end{array}$ & $\begin{array}{c}0.28 \\
(0.15-0.46)\end{array}$ & $\begin{array}{c}0.86 \\
(0.64-0.97)\end{array}$ \\
\hline Presepsin + PCT & 53 & $\begin{array}{c}0.85 \\
(0.55-0.98) \\
\end{array}$ & $\begin{array}{c}0.5 \\
(0.33-0.66) \\
\end{array}$ & $\begin{array}{c}0.35 \\
(0.19-0.55) \\
\end{array}$ & $\begin{array}{c}0.91 \\
(0.71-0.99) \\
\end{array}$ \\
\hline Presepsin + IL-6 & 49 & $\begin{array}{c}0.92 \\
(0.63-1.00)\end{array}$ & $\begin{array}{c}0.44 \\
(0.28-0.62)\end{array}$ & $\begin{array}{c}0.38 \\
(0.21-0.56)\end{array}$ & $\begin{array}{c}0.94 \\
(0.71-1.00)\end{array}$ \\
\hline
\end{tabular}

*Number of investigations

CI: confidence interval, PPH: positive predictive value, NPH: negative predictive value 
Table 8. Biomarkers analysis - differences between patients with gram positive and gram negative bacteraemia

\begin{tabular}{cccc}
\hline & $\begin{array}{c}\text { Gram positive } \\
\text { bacteraemia (mean, SD) }\end{array}$ & $\begin{array}{c}\text { Gram negative } \\
\text { bacteraemia (mean, SD) }\end{array}$ & p-value \\
\hline CRP & $1.70(0.41)$ & $1.74(0.49)$ & 0.830 \\
PCT & $-0.19(0.63)$ & $0.33(0.64)$ & 0.040 \\
IL-6 & $2.01(0.74)$ & $2.81(0.47)$ & 0.005 \\
Presepsín & $2.47(0.13)$ & $2.64(0.29)$ & 0.237 \\
\hline
\end{tabular}

and a marker of the total duration of fever in febrile neutropenic children [5]. However, because of late peak levels of CRP, this marker cannot be use in urgent diagnostics of severe infections. Moreover, we found out poor sensitivity for ability to identify bacteraemia, moderate sensitivity and low PPV for discrimination of sepsis symptomatology. CRP level is also elevated during non-infectious inflammatory states including patients with malignancy, during oncology treatment or after surgery $[3,11]$. This is another documented limitation.

We enrolled presepsin in this study as the last one. Insufficient data probably distorted the outcomes. We determined low cut off levels and weak specificity and PPV in contrast to good sensitivity and high NPV. There are only few existing paediatric studies focused on analysis of presepsin's diagnostic usefulness, mainly in newborns $[18,21]$. Papers considered febrile episodes in childhood oncology patients reported also inconclusive results $[17,20]$. Olad et al. demonstrated that in the absence of other clinically detectable sources of inflammation, presepsin level was significantly higher in blood culture positives, but there was no significant difference between positive and negative blood culture group or between febrile or afebrile group [17]. Urbonas et al. proved that there is no significant difference in presepsin levels between patients with bacteraemia/sepsis and fever of unknown origin [20].

The analysis of a combination of markers showed variations which are suitable in the diagnosis of bacteraemia. The most useful results for blood culture predictions are presented by the combination of CRP with PCT and CRP with IL-6. The combination of PCT with IL-6 is usable too. Each pair with presepsin has very poor specificity and PPV. We noticed slightly higher specificity of combined pairs with presepsin in septic patients compared to a group of patients with proven bacteraemia.

Initially elevated values of PCT and IL-6, are significantly associated with infectious complication causing by gram-negative microorganisms. This finding correlates with known efficiency of cytokines and PCT in predicting gramnegative bacteraemia $[6,34]$. We did not confirm this thesis in presepsin because of insufficient data. The difference between mean presepsin in gram-positives and gram-negatives was not statistically significant even in study published by Olad et al [17].

\section{Conclusion}

In summary, we cannot recommend investigation of CRP in fast diagnostics of bacteraemia/sepsis in paediatric oncology patients because of inconclusive results and its known limitations. The best markers for prediction of bacteraemia are PCT and IL- 6 . While PCT has better specificity and NPV, IL- 6 has better sensitivity and PPV. The most favourable markers for prediction of clinical signs of sepsis are also PCT and IL-6, but in this situation we noticed better sensitivity for IL-6, comparable specificity for PCT and solid NPV for both of these markers. All studied markers are characterized by good NPV. Especially presepsin had a particular strong NPV; and reports slightly better results for prediction of clinical signs of sepsis; however, it is necessary to collect more data for better understanding of the role of presepsin. Therefore we plan to continue enrolling patients on this study.

Highly elevated IL- 6 and PCT at presentation should be an indicator for classification as high risk. IL-6 is also useful tool for monitoring early states of infectious disease because of its fast serum peak and following decline $[4,6,11,12,35]$. In our clinic we start antibiotic therapy in accordance with international 2012 JCO Guideline for management of paediatric febrile neutropenia. We evaluate elements informative for risk stratification included patient-specific factors (including age, malignancy type, and disease status); treatment-specific factors (type and timing of chemotherapy), and episode-specific factors (including height of fever, hypotension, mucositis, blood counts, and available biomarkers - CRP and PCT) [32]. The main criterion for initiating anti-infective therapy remains clinical presentation. Routine usage of interleukin-6, which is characterized by rapid kinetics, can lead to an earlier initiation of antibiotic therapy; potentially before clinical presentation of the infection, and reduce frequency of adverse events. This ability was confirmed in a prospective study of preterm infants [36], but not yet in paediatric oncology patients.

\section{References}

[1] KHAYR W, HADDAD RY, NOOR SA. Infections in hematological malignancies. Dis Mon 2012; 58: 239-249. http:// dx.doi.org/10.1016/j.disamonth.2012.01.001

[2] SANTOLAYA ME, ALVAREZ AM, AVILES CL, BECKER A, MOSSO C et al. Admission clinical and laboratory factors associated with death in children with cancer during a febrile neutropenic episode. Pediatr Infect Dis J 2007; 26: 794-798. http://dx.doi.org/10.1097/INF.0b013e318124aa44

[3] Hakim H, GAUR AH. Initial Management of Fever and Neutropenia in a Child With Cancer - The Past, the Present, and the Future. Clin Emerg Med 2011; 12, 3: 174-184. http:// dx.doi.org/10.1016/j.cpem.2011.07.006

[4] PHILLIPS RS, WADE R, LEHRNBECHER T, STEWART LA, SUTTON AJ. Systematic review and meta-analysis of the value of initial biomarkers in predicting adverse outcome in febrile neutropenic episodes in children and young people with 
cancer. BMC Med 2012; 10: 6. http://dx.doi.org/10.1186/1741$\underline{7015-10-6}$

[5] SKLAVOU R, KARAVANAKI K, CRITSELIS E, KOSSIVA L, GIANNAKI M et al. Variation of serum C-reactive protein (CRP) over time in pediatric cancer patients with febrile illness and its relevance to identified pathogen. Clin Biochem 2012; 45: 1178-1182. http://dx.doi.org/10.1016/j. clinbiochem.2012.07.088

[6] ENGEL A, MACK E, KERN P, KERN WV. An analysis of interleukin-8, interleukin-6 and C-reactive protein serum concentrations to predict fever, gram-negative bacteremia and complicated infection in neutropenic cancer patients. Infection 1998; 26: 213-221. http://dx.doi.org/10.1007/ BF02962366

[7] SECMEER G, DEVRIM I, KARA A, CEYHAN M, CENGIZ B et al. Role of procalcitonin and CRP in differentiating a stable from a deteriorating clinical course in pediatric febrile neutropenia. J Pediatr Hematol Oncol 2007; 29: 107-111. http:// dx.doi.org/10.1097/MPH.0b013e3180320b5b

[8] SAKR Y, SPONHOLZ C, TUCHE F, BRUNKHORST F, REINHART K. The role of procalcitonin in febrile neutropenic patients: review of the literature. Infection 2008; 36: 396-407. http://dx.doi.org/10.1007/s15010-008-7374-y

[9] KNUDSEN TB, KRISTIANSEN TB. Issues pertaining to data extraction and classification and publication bias in metaanalysis of the diagnostic accuracy of markers for bacterial infection. Clin Infect Dis 2005; 40: 1372-1373; author reply 1373-1374. http://dx.doi.org/10.1086/429507

[10] PERSSON L, ENGERVALL P, MAGNUSON A, VIKERFORS T, SODERQUIST B et al. Use of inflammatory markers for early detection of bacteraemia in patients with febrile neutropenia. Scand J Infect Dis 2004; 36: 365-371. http://dx.doi. org/10.1080/00365540410020217

[11] REINHART K, BAUER M, RIEDEMANN NC, HARTOG CS. New approaches to sepsis: molecular diagnostics and biomarkers. Clin Microbiol Rev 2012; 25: 609-634. http:// dx.doi.org/10.1128/CMR.00016-12

[12] TAMAYO E, FERNANDEZ A, ALMANSA R, CARRASCO E, HEREDIA $M$ et al. Pro- and anti-inflammatory responses are regulated simultaneously from the first moments of septic shock. Eur Cytokine Netw 2011; 22: 82-87.

[13] URBONAS V, EIDUKAITE A, TAMULIENE I. Increased interleukin-10 levels correlate with bacteremia and sepsis in febrile neutropenia pediatric oncology patients. Cytokine 2012; 57: 313-315. http://dx.doi.org/10.1016/j. cyto.2011.11.012

[14] MIEDEMA KG, DE BONT ES, OUDE NIJHUIS CS, VAN VLIET D, KAMPS WA et al. Validation of a new risk assessment model for predicting adverse events in children with fever and chemotherapy-induced neutropenia. J Clin Oncol 2011; 29: e182-184; author reply e185.

[15] LIU B, CHEN YX, YIN Q, ZHAO YZ, LI CS. Diagnostic value and prognostic evaluation of Presepsin for sepsis in an emergency department. Crit Care 2013; 17: R244. http:// dx.doi.org/10.1186/cc13070

[16] PIETERIS L, BAKSYTE G, CESNAITIS T, VITKAUSKIENE A, MACAS A. New strategies in sepsis diagnosis. Acta Med
Lituanica 2012; 19: 160-162. http://dx.doi.org/10.6001/actamedica.v19i3.2440

[17] OLAD E, SEDIGHI I, MEHRVAR A, TASHVIGHI M, FALLAHAZAD V et al. Presepsin $(\operatorname{scd} 14)$ as a marker of serious bacterial infections in chemotherapy induced severe neutropenia. Iran J Pediatr 2014; 24: 715-722.

[18] POGGI C, BIANCONI T, GOZZINI E, GENEROSO M, DANI C. Presepsin for the detection of late-onset sepsis in preterm newborns. Pediatrics 2015; 135: 68-75. http://dx.doi. org/10.1542/peds.2014-1755

[19] STUBLJAR D, KOPITAR AN, GROSELJ-GRENC M, SUHADOLC K, FABJAN T et al. Diagnostic accuracy of presepsin (sCD14-ST) for prediction of bacterial infection in cerebrospinal fluid samples from children with suspected bacterial meningitis or ventriculitis. J Clin Microbiol 2015; 53: 1239-1244. http://dx.doi.org/10.1128/JCM.03052-14

[20] URBONAS V, EIDUKAITE A, TAMULIENE I. The predictive value of soluble biomarkers (CD14 subtype, interleukin-2 receptor, human leucocyte antigen-G) and procalcitonin in the detection of bacteremia and sepsis in pediatric oncology patients with chemotherapy-induced febrile neutropenia. Cytokine 2013; 62: 34-37. http://dx.doi.org/10.1016/j. cyto. 2013.02 .030

[21] OSMAN AS, AWADALLAH MG, EL-MAGEED TABL HA, ABED NT, GOUDAH ESS. Presepsin as a Novel Diagnostic Marker in Neonatal Septicemia. Egypt J Med Microbiol 2015; 24: 21-26. http://dx.doi.org/10.12816/0024924

[22] DUPUY AM, PHILIPPART F, PEAN Y, LASOCKI S, CHARLES PE et al. Role of biomarkers in the management of antibiotic therapy: an expert panel review: I - currently available biomarkers for clinical use in acute infections. Ann Intensive Care 2013; 3: 22. http://dx.doi.org/10.1186/2110$\underline{5820-3-22}$

[23] BOMELA HN, BALLOT DE, CORY BJ, COOPER PA. Use of $\mathrm{C}$-reactive protein to guide duration of empiric antibiotic therapy in suspected early neonatal sepsis. Pediatr Infect Dis J 2000; 19: 531-535. http://dx.doi.org/10.1097/00006454200006000-00008

[24] JASWAL RS, KAUSHAL RK, GOEL A, PATHANIA K. Role of C-reactive protein in deciding duration of antibiotic therapy in neonatal septicemia. Indian Pediatr 2003; 40: 880-883.

[25] MANZANO S, BAILEY B, GIRODIAS JB, GALETTOLACOUR A, COUSINEAU J et al. Impact of procalcitonin on the management of children aged 1 to 36 months presenting with fever without source: a randomized controlled trial. Am J Emerg Med 2010; 28: 647-653. http://dx.doi.org/10.1016/j. ajem.2009.02.022

[26] STOCKER M, FONTANA M, EL HELOU S, WEGSCHEIDER K, BERGER TM. Use of procalcitonin-guided decision-making to shorten antibiotic therapy in suspected neonatal early-onset sepsis: prospective randomized intervention trial. Neonatology 2010; 97: 165-174. http://dx.doi. org/10.1159/000241296

[27] DEFORGE LE, REMICK DG. Kinetics of TNF, IL-6, and IL-8 gene expression in LPS-stimulated human whole blood. Biochem Biophys Res Commun 1991; 174: 18-24. http://dx.doi. org/10.1016/0006-291X(91)90478-P 
[28] BRODSKA H, DRABEK T, MALICKOVA K, KAZDA A, VITEK A et al. Marked increase of procalcitonin after the administration of anti-thymocyte globulin in patients before hematopoietic stem cell transplantation does not indicate sepsis: a prospective study. Crit Care 2009; 13: R37. http:// dx.doi.org/10.1186/cc7749

[29] SHOZUSHIMA T, TAKAHASHI G, MATSUMOTO N, KOJIKA M, OKAMURA Y et al. Usefulness of presepsin (sCD14-ST) measurements as a marker for the diagnosis and severity of sepsis that satisfied diagnostic criteria of systemic inflammatory response syndrome. J Infect Chemother 2011; 17: 764-769. http://dx.doi.org/10.1007/s10156-011-0254-x

[30] CASTELLI GP, POGNANI C, MEISNER M, STUANI A, BELLOMI D et al. Procalcitonin and C-reactive protein during systemic inflammatory response syndrome, sepsis and organ dysfunction. Crit Care 2004; 8: R234-242.

[31] AMMANN RA, BODMER N, HIRT A, NIGGLI FK, NADAL $\mathrm{D}$ et al. Predicting adverse events in children with fever and chemotherapy-induced neutropenia: the prospective multicenter SPOG $2003 \mathrm{FN}$ study. J Clin Oncol 2010; 28: 2008-2014. http://dx.doi.org/10.1200/JCO.2009.25.8988

[32] LEHRNBECHER T, PHILLIPS R, ALEXANDER S, ALVARO F, CARLESSE $\mathrm{F}$ et al. Guideline for the management of fever and neutropenia in children with cancer and/or undergoing hematopoietic stem-cell transplantation. J Clin Oncol 2012; 30: 4427-4438. http://dx.doi.org/10.1200/JCO.2012.42.7161

[33] LEHRNBECHER T, VENZON D, DE HAAS M, CHANOCK SJ, KUHL J. Assessment of measuring circulating levels of interleukin-6, interleukin-8, C-reactive protein, soluble Fc gamma receptor type III, and mannose-binding protein in febrile children with cancer and neutropenia. Clin Infect Dis 1999; 29: 414-419. http://dx.doi.org/10.1086/520224

[34] URBONAS V, EIDUKAITE A. Diagnostic accuracy of procalcitonin, interleukin- 6 and interleukin- 8 for predicting Gram-negative bacteremia in febrile neutropenia patients with acute lymphoblastic leukemia. Acta Med Lituanica 2014; 21: 178-181.

[35] BUCK C, BUNDSCHU J, GALLATI H, BARTMANN P, POHLANDT F. Interleukin-6: a sensitive parameter for the early diagnosis of neonatal bacterial infection. Pediatrics 1994; 93: 54-58.

[36] KUSTER H, WEISS M, WILLEITNER AE, DETLEFSEN $S$, JEREMIAS I et al. Interleukin-1 receptor antagonist and interleukin-6 for early diagnosis of neonatal sepsis 2 days before clinical manifestation. Lancet 1998; 352: 1271-1277. http://dx.doi.org/10.1016/S0140-6736(98)08148-3 